\title{
Effectiveness of hip protectors for preventing hip fractures in elderly people: systematic review
}

Martyn J Parker, William J Gillespie, Lesley D Gillespie

\begin{abstract}
Objectives To present the updated results of systematic review of the current evidence for the effectiveness of hip protectors from reports of completed randomised trials, and to explore the evolution of that evidence.

Design Systematic review with meta-analysis.

Data sources Cochrane Bone, Joint, and Muscle Trauma Group trials register (January 2005), Cochrane central register of controlled trials (Cochrane Library Issue 1, 2005), Medline (1966 to January 2005), Embase (1988 to January 2005), and CINAHL (1982 to December 2004). Other databases and reference lists of relevant articles were searched and some trialists were contacted.
\end{abstract}

Review methods Randomised or quasirandomised controlled trials reporting the incidence of hip fractures, pelvic fractures, and other fractures in elderly people offered hip protectors compared with a control group that was not.

Results Outcomes for fracture were available from 14 randomised and quasirandomised trials. Pooling of data from 11 trials carried out in nursing or residential care settings, including six cluster randomised studies, showed evidence of a marginally statistically significant reduction in incidence of hip fracture (relative risk $0.77,95 \%$ confidence interval 0.62 to 0.97). Pooling of data from three individually randomised trials of 5135 community dwelling participants showed no reduction in hip fracture incidence with provision of hip protectors (1.16, 0.85 to 1.59). No evidence was found of any significant effect of hip protectors on incidence of pelvic or other fractures. No important adverse effects of hip protectors were reported, but compliance, particularly in the long term, was poor.

Conclusions On the basis of early reports of randomised trials, hip protectors were advocated. Accumulating evidence indicates that hip protectors are an ineffective intervention for those living at home and that their effectiveness in an institutional setting is uncertain.

\section{Introduction}

Hip fracture is the commonest reason for admission of elderly people to an acute orthopaedic ward. An estimated 1.3 million hip fractures occurred worldwide in 1990, and incidence continues to rise. Such fractures may result in death or permanent disability and account for an estimated $0.1 \%$ of the global burden of disease. ${ }^{1}$ A hip fracture is generally the result of a fall. Hip protectors consist of specifically designed padding worn around the hip to reduce the impact of a fall.

We previously published a systematic review of randomised trials that investigated the effectiveness of hip protectors. ${ }^{2}$ Five trials totalling 1681 elderly participants at risk of hip fracture were included in that review. We concluded that hip protectors seemed to reduce the risk of a hip fracture after a fall in elderly residents of nursing homes. A large cluster randomised study was subsequently published that seemed to strengthen the evidence for the effectiveness of hip protectors. ${ }^{3}$

In the five years since the publication of the first review, the inclusion of further studies in updates has led us to revise our original conclusions. In this paper we report on the most recent update of the systematic review ${ }^{4}$ and discuss the additional information from the accumulation of evidence since the mid-1990s.

\section{Methods}

We carried out a systematic review of the current evidence for the effectiveness of hip protectors on the basis of reports of completed randomised and quasirandomised trials. The null hypothesis was that hip protectors have no effect on the incidence of hip fracture in elderly people. We included randomised or quasirandomised trials that compared the incidence of hip, pelvic, and other fractures in elderly people of either sex allocated to the provision of hip protectors or no provision.

We searched the Cochrane Bone, Joint, and Muscle Trauma Group trials register (January 2005), the Cochrane central register of controlled trials (Cochrane Library issue 1, 2005), Medline (Ovid, 1966 to January 2005), Embase (Ovid, 1988 to January 2005), CINAHL (Ovid, 1982 to December 2004), BioMed Central, National research register issue 4, 2004, and current controlled trials. We also searched reference lists of retrieved articles, and corresponded with groups known to be involved in the evaluation of hip protectors. We applied no language restrictions.

Two reviewers independently extracted data for each study. The outcomes sought were incidence of hip fractures over the study period and incidence of pelvic fractures (pubic ramus and others) and other fractures, compliance, and reported adverse events from wearing hip protectors. Two reviewers independently assessed each trial for methodological quality. Differences were resolved by discussion. The main assessment of methodology was by concealment of allocation at randomisation. We also assessed a further seven aspects of methodology (box).

For each study we calculated the relative risk with 95 per cent confidence limits for the incidence of hip fractures, pelvic fractures, and other fractures. We used generic inverse variance

Details of included studies are on bmj.com 
to pool data from individually randomised studies, and from cluster randomised studies for which the intracluster correlation coefficient was known or could be calculated. ${ }^{5} \mathrm{~A}$ standard $\chi^{2}$ test in conjunction with the $\mathrm{I}^{2}$ statistic was used to test heterogeneity between trials in each analysis. ${ }^{6}$ We explored evidence of statistical heterogeneity using sensitivity analysis with and without outlying studies.

\section{Results}

We identified 28 primary studies and one systematic review for possible inclusion in our study. ${ }^{7}$ Ten studies were excluded: three were randomised trials of a multifactorial intervention that included hip protectors, six were observational studies with no randomisation, and one was a randomised study with inadequate

\section{Quality assessment items and possible scores of randomised or quasirandomised trials assessing effectiveness of hip protectors}

Item 1: was there clear concealment of allocation, either of individual participants or of clusters of individuals?

Score 3 if allocation clearly concealed (for example, numbered sealed opaque envelopes drawn consecutively. This included cluster randomised trials in which allocation of clusters was clearly concealed and no participants joined the cluster subsequently)

Score 2 if there was a possible chance of disclosure before allocation (this included cluster randomised trials in which initial allocation was clearly concealed but in which recruitment into clusters continued or may have continued after the cluster allocation was known)

Score 1 if the method of allocation concealment or randomisation was not stated or was unclear

Score 0 if allocation was clearly not concealed (for example, quasirandomisation by even or odd date of birth)

Item 2: were the inclusion and exclusion criteria clearly defined?

Score 1 if text stated type of participants included and those excluded, otherwise score 0

Item 3: were the outcomes of trial participants who withdrew or were excluded after allocation described and included in an intention to treat analysis?

Score 1 if yes or text states that no withdrawals occurred or data are presented clearly showing participant flow, which allows this to be inferred, otherwise score 0

Item 4: were the treatment and control groups adequately described at entry and if so were the groups well matched or appropriate covariate adjustment made?

Score 1 if at least four admission details given (for example, age, sex, mobility, function score, mental test score) with either no important difference between groups or appropriate adjustment made, otherwise score 0

Item 5: were the care programmes other than the trial options similar?

Score 1 if it was stated or could be inferred that no variable other than the trial option was systematically different between the intervention and control groups, otherwise score 0

Item 6: was loss to follow-up reported and, if so, were less than 5\% of participants lost to follow-up?

Score 1 if yes, otherwise score 0 . Deaths during the study period were not included as loss to follow-up

Item 7: was compliance with treatment monitored?

Score 1 if yes, otherwise score 0

Item 8: was follow-up active or scheduled as opposed to simple reporting of incidents as they occurred?

Score 1 if yes, otherwise score 0 data. Three studies were ongoing, ${ }^{4}$ and a further study, of acceptance of and adherence to hip protectors, reported no fractures. ${ }^{8}$ We therefore analysed data from 14 randomised and quasirandomised trials in the updated review. ${ }^{3-21}$ The mean age of participants in the included studies ranged from 78 to 86 years, with most being women. Eleven studies recruited mainly or exclusively residents in institutional care, ${ }^{3}{ }^{11}{ }^{13-21}$ and three recruited people mainly or exclusively living in the community. ${ }^{9} 10^{12}$ The methodological quality scores ranged from 4 to 9 out of a possible 10. See bmj.com for the characteristics of the included studies. Detailed results of the methodology assessment are listed in the updated Cochrane review. ${ }^{4}$

Figure 1 shows the incidence of hip fractures in studies carried out in institutions. The pooled data showed evidence of a statistically significant reduction in incidence of hip fractures in the groups allocated to provision of hip protectors (relative risk $0.77,95 \%$ confidence interval 0.62 to 0.97 ). This reduction is of marginal significance, with wide confidence intervals, and is sensitive to the inclusion or removal from the analysis of two large cluster randomised studies that contributed to heterogeneity in the overall analysis $\left(\mathrm{P}<0.10, \mathrm{I}^{2}=39.9 \%\right){ }^{22}$

The significant reduction in hip fracture was not apparent on pooling only the individually randomised studies $(0.86,0.54$ to 1.34). This subgroup showed no evidence of significant heterogeneity $\left(\mathrm{P}=0.68, \mathrm{I}^{2}=1.6 \%\right)$. Within the cluster randomised subgroup, however, there was significant statistical heterogeneity $\left(\mathrm{P}=0.03, \mathrm{I}^{2}=59.4 \%\right)$. This heterogeneity was explored by carrying out sensitivity analyses. It was found to be accounted for by the different outcomes of two large studies, ${ }^{3}{ }^{20}$ the $95 \%$ confidence intervals of which did not overlap. Testing for interaction showed that the results from Kannus et $\mathrm{al}^{3}$ were significantly different from the remainder of the cluster randomised trials $(\mathrm{P}=0.03)$, as were the results from O'Halloran et al $(\mathrm{P}=0.001){ }^{20}$ Removal of the Kannus et al data from the analysis resulted in loss of the significant evidence of effectiveness. If O'Halloran et al was removed from the analysis the significant effect of hip protectors in reducing the incidence of hip fractures remained.

Figure 2 shows the relative risks and 95\% confidence intervals from the three individually randomised studies that recruited elderly people living in the community. These studies, the results of which were homogeneous, found no significant reduction in the occurrence of hip fractures between groups $(1.16,0.85$ to 1.59$)$.

Most studies recorded the incidence of fractures of the pelvis, including the pubic rami. No evidence was found that hip protectors reduced the incidence of pelvic fracture. Seven individually randomised studies identified 21 pelvic fractures among 2654 participants allocated to hip protectors compared with 28 among 3836 controls $(0.96,0.54$ to 1.69$)$. Hip protectors seemed to have no effect on the incidence of other fall related fractures $(0.85,0.70$ to 1.05$)$. Problems with compliance- the acceptance of, and adherence to, the use of hip protectors-were reported in all included studies.

\section{Discussion}

The bulk of the evidence from the initial cluster randomised trials up to 2001 on hip fractures in elderly people living in institutional care suggested that hip protectors significantly reduced the incidence of hip fracture, and their use has been widely adopted in institutional settings. This significant protective effect has not been confirmed by data from individually randomised studies. The results of the two more recent large cluster 
randomised studies, ${ }^{320}$ which between them contributed over $60 \%$ of all participants in our analysis, showed significant heterogeneity. Design issues in these two studies may have contributed to the heterogeneity.

Selection bias is a risk in cluster randomised trials that recruit participants over time, as admission to a particular nursing home or ward may not have been a random event. Differences between groups of participants in rates of falls and fractures might be confounded through systematic differences in other aspects of care between nursing homes or wards.

Reports of the effectiveness of hip protectors may have been misleading owing to publication bias or flaws in the design, conduct, and reporting of the early cluster randomised studies. Four of the six included cluster randomised studies that dominated the earlier literature (including our first Cochrane review) were influential in encouraging the wider introduction of hip protectors. In the primary reports of these four studies, although allocation was by institution, analysis was by individual without allowing for the effect of clustering. ${ }^{341518}$ Two more recent cluster randomised studies reported appropriate analyses. ${ }^{19}{ }^{20}$ In our initial review we were able only to provide exploratory analyses of cluster randomised trials; it has now been possible with additional information from the trialists to carry out appropriate statistical analysis for clustering, enabling a more accurate estimate of the effect size than in previous systematic reviews. ${ }^{2}{ }^{7}$

Our Cochrane review gives details of the heterogeneity among the populations studied in respect of their baseline risk of fracture. Many of the trials included in this review targeted people at particularly high risk of hip fracture. Lauritzen et $\mathrm{al}^{18}$ reported that the annual incidence of hip fractures in Denmark during the 1989 study period was 18 per 1000 for the general population aged 70 years or more; in the group studied, however, the incidence was 81 per 1000 (95\% confidence interval 55 to 108). The comparison groups were those allocated to hip protectors or not. In practice, the use of hip protectors seems to have varied between trials and within trials. A systematic review reported that acceptance ranged from $37 \%$ to $72 \%$ (median 68\%) and compliance varied between 20\% and 92\% (median 56\%). ${ }^{23}$ Non-compliance presents both practical challenges in the healthcare setting and problems in analysis and

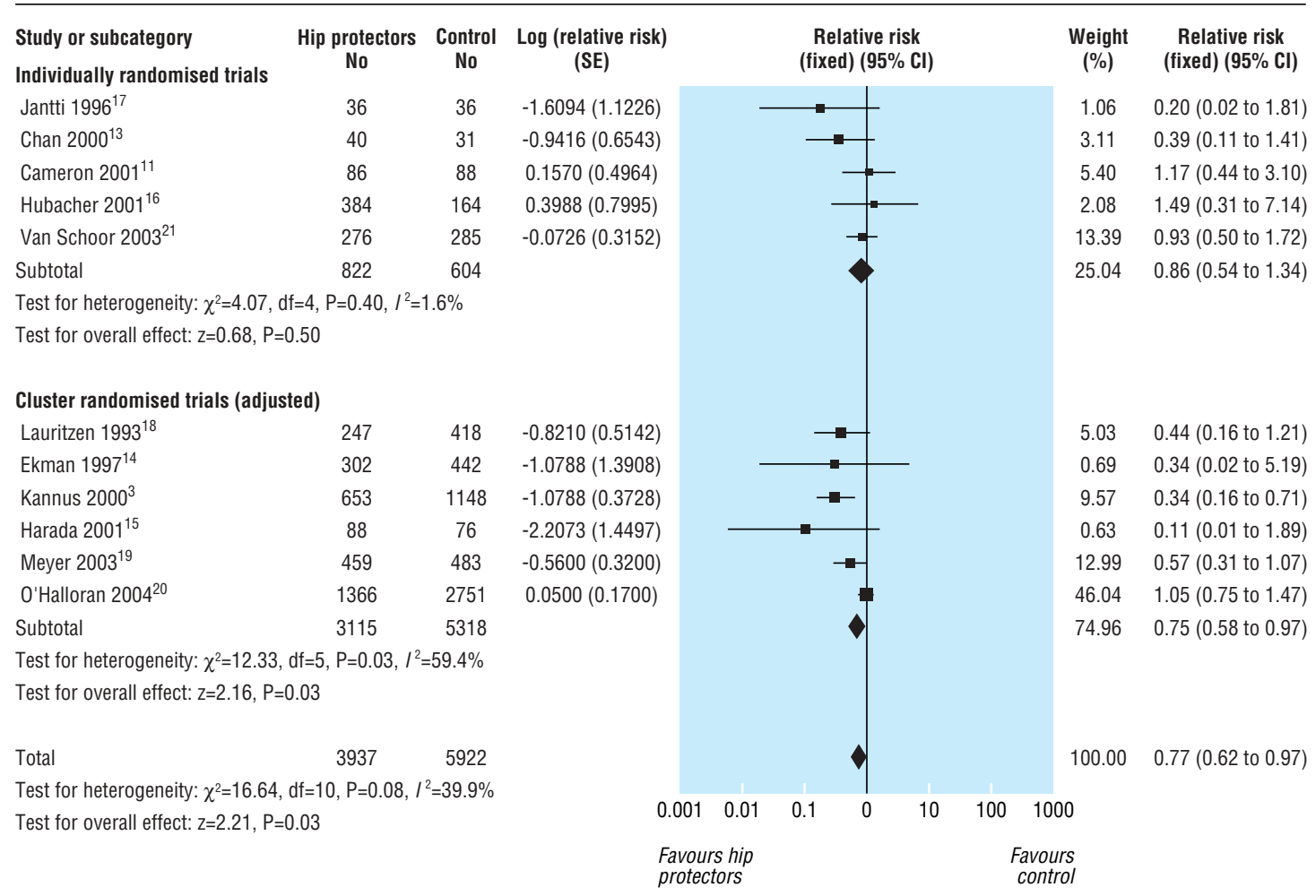

Fig 1 Incidence of hip fractures in elderly participants provided with hip protectors or not in an institutional setting

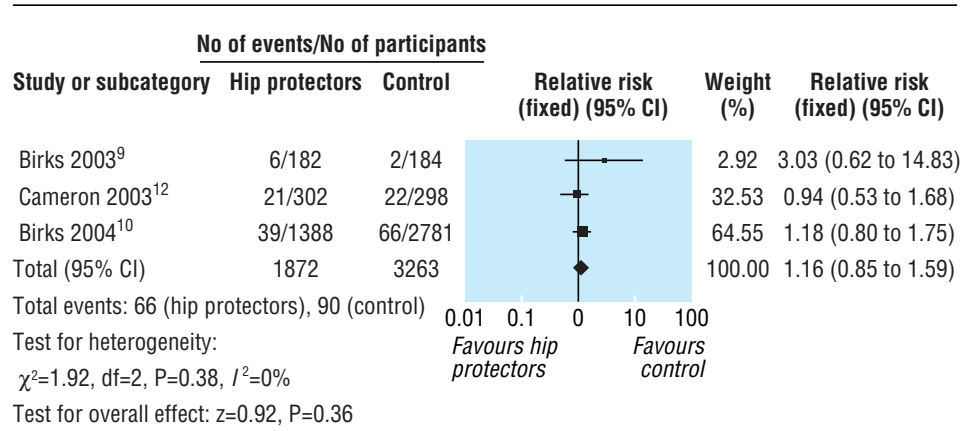

Fig 2 Incidence of hip fractures in elderly participants provided with hip protectors or not in the community 


\section{Research}

interpretation of data. The hip protectors may be difficult to fit and be uncomfortable. ${ }^{8}{ }^{16}$ Older people may find them unattractive, and even those with a previous hip fracture may not use them..$^{13}$ Also, hip protectors may cause skin irritation.

Since the previous update of our Cochrane review, another systematic review on this topic has been published. ${ }^{7}$ These investigators agreed with our earlier analyses and conclusions on the ineffectiveness of hip protectors in community dwelling people. Although their inclusion criteria were stricter than ours, they concluded that hip protectors were effective in older people in an institutional setting. However their review included Van Schoor et $\mathrm{al}^{21}$ in the community dwelling analysis. That study confirmed that of the 561 residents, 38 lived in apartment houses for elderly people, 247 in homes for elderly people, and 276 in nursing homes (N M Van Schoor, personal communication, 2005). Admission to homes or nursing homes was based on the need for extra care. We therefore feel justified in including that trial in the analysis of institutional settings.

The studies included in this review concerned several designs of hip protector. We note that the production of hip protectors has been largely unregulated. It is not possible to be sure that the different hip protectors used were of equal effectiveness for preventing fractures. In addition, compliance may vary for the different types of hip protectors, and standard definitions for adherence have been proposed. ${ }^{24}$ Trials in progress are examining both effectiveness of hip protectors in a range of institutional and community settings and ways of improving acceptance and adherence. Their results may help resolve the current uncertainty. Further studies on hip protectors might be indicated if changes to their design improve acceptance and adherence. Such studies should have sufficient study power.

Contributors: All authors designed the study, reviewed the studies identified, and checked the data. MJP wrote the first draft of the article, and WJG and LDG provided substantive subsequent contributions. MJP is guarantor.

Funding: None.

Competing interests: None declared.

\section{What is already known on this topic}

Hip protectors have been advocated to prevent hip fractures in elderly people

\section{What this study adds}

Early randomised trials on elderly institutionalised people suggested that hip fracture incidence was reduced in those using hip protectors

Subsequent randomised studies found hip protectors to be ineffective for those living at home and questioned their effectiveness in institutionalised people

Compliance with wearing hip protectors is poor
Ethical approval: Not required.

1 Johnell O, Kanis JA. An estimate of the worldwide prevalence, mortality and disability associated with hip fracture. Osteoporos Int 2004:15:897-902.

2 Parker MJ, Gillespie LD, Gillespie WJ. Hip protectors for preventing hip fractures in the elderly. Cochrane Database Syst Rev 1999;(3):CD001255.

3 Kannus P, Parkkari J, Niemi S, Pasanen M, Palvanen M, Jarvinen M, et al. Prevention of hip fracture in elderly people with use of a hip protector. N Engl J Med 2000;343:150613

4 Parker MJ, Gillespie LD, Gillespie WJ. Hip protectors for preventing hip fractures in older people. Cochrane Database Syst Rev 2005;(3):CD001255.

5 Higgins JPT, Green S, eds. Cochrane Handbook for Systematic Reviews of Interventions 4.2.4 [updated March 2005]; Section 8.5.1.1. In: The Cochrane Library, Issue 2. Chichester: Wiley, 2005.

6 Higgins JP, Thompson SG, Deeks JJ, Altman DG. Measuring inconsistency in meta-analysis. $B M J$ 2003:327:557-60.

7 Sawka AM, Boulos P Beattie K, Thabane L, Papaioannou A, Gafni A et al. Do hip protectors decrease the risk of hip fracture in institutional- and community-dwelling elderly? A systematic review and meta-analysis of randomized controlled trials. Osteoporos Int 2005 Mar 8; [epub ahead of print].

8 Villar MTA, Hill P, Inskip H, Thompson P, Cooper C. Will elderly rest home residents wear hip protectors? Age Ageing 1998;27:195-8.

9 Birks Y, Hildreth R, Campbell P, Sharpe C, Torgerson D, Watt I. A randomised controlled trial of hip protectors for the prevention of second hip fractures. Age Ageing 2003;32:442-4.

10 Birks YF, Porthouse J, Addie C, Lounghney L, Saxon L, Braverstock M, et al. Randomised controlled trial of hip protectors amongst women living in the community Osteoporos Int 2004:15:701-6.

11 Cameron ID, Venman J, Kurrle SE, Lockwood K, Bicks C, Cumming RG, et al. Hip protectors in aged-care facilities: a randomized trial of use by individual higher-risk residents. Age Ageing 2001;30:477-81.

12 Cameron ID, Cumming RG, Kurrle SE, Quine S, Lockwood K, Salkeld G, et al. A randomised trial of hip protector use by frail elderly older women living in their own homes. Inj Prev 2003;9:138-41.

13 Chan DK, Hillier G, Coore M, Cooke R, Monk R, Mills J, et al. Effectiveness and acceptability of a newly designed hip protector: a pilot study. Arch Gerontol Geriatr 2000;30:25-34.

14 Ekman A, Mallmin H, Michaelsson N, Ljunghall S. External hip protectors to prevent osteoporotic hip fractures. Lancet 1997;350:563-4.

15 Harada A, Mizuno M, Takemura M, Tokuda H, Okuizumi H, Niino N. Hip fracture prevention trial using hip protectors in Japanese nursing homes. Osteoporos Int 2001;12:215-21.

16 Hubacher M, Wettstein A. Acceptance of hip protectors for hip fracture prevention in nursing homes. Osteoporos Int 2001;12:794-9.

17 Jantti P, Aho H, Maki-Jokela L. Turvahousut lonkanseudun murtumien ehkäisyssä. [Protector trousers in prevention of hip fractures.] Suomen Lõõkôrilehti 1996;51(32):3387-9. [In Finnish.]

18 Lauritzen JB, Petersen MM, Lund B. Effect of external hip protectors on hip fractures. Lancet 1993;341:11-3.

19 Meyer G, Warnke A, Bender R, Muhlhauser I. Effect on fractures of increased use of hip protectors in nursing homes: cluster randomised controlled trial. BMJ 2003;326:6-8.

20 O'Halloran PD, Cran GW, Beringer TRO, Kernohan G, O'Neill C, Orr J, et al A cluster randomised controlled trial to evaluate a policy of making hip protectors available to randomised controlled trial to evaluate a policy of makn
residents of nursing homes. Age Ageing 2004;33:582-8.

21 Van Schoor NM, Smit JH, Twisk JWR, Bouter LM, Lips P. Prevention of hip fractures by external hip protectors; a randomized controlled trial. JAMA 2003;289(15):1957-62.

22 Higgins JPT, Green S, eds. Cochrane Handbook for Systematic Reviews of Interventions 4.2.4 [updated March 2005]; Section 8.7.2. In: The Cochrane Library, Issue 2. Chichester: Wiley, 2005.

23 Van Schoor NM, Deville WL, Bouter LM, Lips P. Acceptance and compliance with external hip protectors: a systematic review of the literature. Osteoporos Int 2002;13(12):917-24.

24 Kurrle SE, Cameron ID, Quine S. Predictors of adherence with the recommended use of hip protectors. J Gerontol A Biol Sci Med Sci 2004;59(9):M958-61.

(Accepted 10 January 2006)

doi $10.1136 /$ bmj.38753.375324.7C

Orthopaedic Department, Peterborough and Stamford Hospitals NHS Foundation Trust, Peterborough District Hospital, Peterborough PE3 6DA

Martyn J Parker research fellow

Hull York Medical School, University of Hull, Hull HU6 7RX William J Gillespie dean

Department of Health Sciences, University of York, Heslington, York YO10 5DD Lesley D Gillespie research fellow

Correspondence to: M J Parker martyn.parker@pbh-tr.nhs.uk 